\title{
Türkçe ve Bulgarcada erbap sözcügünün anlam ve kullanımı üzerine
}

\section{Meryem SALIM AHMED1} APA: Salim Ahmed, M. (2019). Türkçe ve Bulgarcada erbap sözcüğünün anlam ve kullanımı üzerine.
RumeliDE Dil ve Edebiyat Araşttrmalar Dergisi, (ö5), 59-68. DOI: 10.29000/rumelide.606069.

\section{$\ddot{O} \mathbf{z}$}

Tarihi dönemlerde diller arası ilişkiler dolaylı yollarla veya doğrudan gerçekleşmiştir. Coğrafi yakınlığın da getirmiş olduğu bir sonuç olarak sosyal, siyasi ve askeri ilişkiler içerisinde bulunmuş olan komşu diller arasında ise doğrudan dil ilişkileri gerçekleşmiştir. Osmanlıların Balkanları fethetmesiyle birlikte, bölgedeki toplulukların yapısında büyük değişiklikler meydana gelmiştir. Bunlardan biri de dil alanında açıkça görülmektedir. Binlerce Türkçe sözcük Balkan dillerine girmiştir. Bu dillerden biri Bulgarcadır. Bulgarcadaki Türkçe ve Türkçe vasıtasıyla girmiş Arapça ve Farsça kökenli sözcükler en eski dönemlerden günümüze kadar eşsiz dilsel malzeme sayılmaktadır. Araştırmacıların bir kısmı sadece Bulgarca edebi dildeki Türkçe sözcükleri ele alırken, bir diğerleri ise yazılı ve sözlü dili ve kültürü birlikte ele almaktadırlar. Günümüzde Bulgarcadaki Türkçe alıntı sözcüklerin belli bir miktarı jargon dilinde, konuşma dilinde ve ağızlarda sıklıkla kullanılmaya devam etmektedir. Çalışmamızda, eskiden beri kullanımı yaygın olan erbap sözcügünün Türkçe ve Bulgarcadaki anlamları ve her iki dildeki kullanımları üzerinde durulmaktadır.

Anahtar kelimeler: Türkçe, Bulgarca, erbap, anlam, kullanım.

\section{The meaning and usage of the word erbap in Turkish and Bulgarian}

\begin{abstract}
In the different historical periods, the relations between languages were direct or indirect. As a result of geographical closeness, direct language relations emerged between neighboring languages which were in social, political and military relations. With the Ottoman conquest of the Balkans, major changes occurred in the structure of the communities in the region. One of them is clearly seen in the linguistic area. Thousands of Turkish words have entered the Balkan languages. One of these languages is Bulgarian. Turkish words, and Arabic and Persian words, which were introduced through Turkish into Bulgarian are considered as linguistic material until today. However, some of the researchers deal only with the Turkish words in Bulgarian literary language, while others deal with both written and spoken language and culture. A certain amount of the borrowed Turkish words in Bulgarian nowadays is frequently used in jargon, spoken language and dialects. In our study will be emphasized the meaning and usage of the word erbap, which has been used from of old in both Turkish and Bulgarian.
\end{abstract}

Keywords: Turkish, Bulgarian, erbap, meaning, usage. 


\section{Giriş}

Osmanlılar, uzun tarihi geçmişi boyunca Bulgar halkıyla karşılıklı ilişkilerde bulunmuşlardır. Bu iki toplumun akraba olmayan dilleri arasında da alış veriş sonucu bir dilden ötekine çeşitli dil unsurları geçmeye başlamıştır. Bulgarca köken bakımından Hint-Avrupa dil ailesinin, Slav dilleri alt kolunun, Güney Slav grubunun, Güneydoğu Slav dillerinin bir üyesidir. Bulgarca Güney Slav grubuna ait olmakla birlikte Balkan Dil Birliği’nin de bir parçasıdır. Bulgarların Türklerle ilişkileri Bulgar dilinin tarihi gelişiminde önemli rol oynamış, dil yapısında değişimlere sebebiyet vermiştir.

Bulgarcadaki Türkçe söz varlığı birçok araştırmacının inceleme konusu olmuştur. Aslında Türkçe sözcükler konusunun araştırılması bir çalışmanın kapsamı ve dönemleri ile ilgilidir. Araştırmacıların bir kısmı Bulgarcada sadece edebi dildeki Türkçe sözcükleri ele alırken, diğerleri ise yazılı ve sözlü dili ve kültürü birlikte incelemektedirler. Günümüzde Bulgarcadaki Türkçe alıntı sözcüklerin belli bir miktarı, konuşma dilinde, jargon dilinde ve ağızlarda sıklıkla kullanılmaya devam etmektedir. Bunların bir çoğu, tarihi süreç içinde temel anlamının yanında pek çok yan anlam kazanmıştır. Bu sözcüklerden biri, çalışmamızın konusunu oluşturan, eskiden beri Türkçede kullanımı yaygın olan erbap sözcügüdür. Bulgu ve tespitlerimizin, ünlü dilci Doğan Aksan'ın da belirttiği gibi, Türkçenin yayıldığı çeşitli alanlar için yüzyıllara göre anlam olaylarının saptanması hem Türkçe hem de dilbilimi yönünden, özellikle değişmelerdeki etkenlerin aydınlatılması bakımından yararlı olacağı şüphesizdir (Aksan, 1978: 137138).

Çalışmamızda erbap sözcüğünün Türkçe ve Bulgarcadaki kullanımları ve her iki dildeki anlamları üzerinde durulacaktır.

Erbap denilince önce "işini iyi bilen, usta bir kimse" akla gelmektedir. Günümüzde herhangi bir meslek dalında uzmanlaşmış, profesyonellik mertebesine yükselmiş kişi için "işin erbabı" deyimini kullanmayan yoktur. Sözcüğünün anlam çerçevesinden yola çıkarak önce Türkçedeki anlam ve kullanımlarını ele almak uygun olur.

\section{Erbap sözcüğünün sözlük anlamı}

Türkçede erbap sözcüğü Arapça kökenli bir alıntı olarak kullanılmaktadır. Arapçada, "sahip oldu, ıslah etti, efendi/lider oldu, yetiştirdi ve topladı" anlamları ifade eden "rabbe" sözcüğünün çoğul biçimi olan erbap, Türkçe Sözlükte "bir işten anlayan, bir işi iyi yapan kimse" anlamlarıyla geçmektedir (TS 1998: 717). Sözlük ve ansiklopedik kaynaklarda genellikle sözcüğün iki anlamına odaklanılmaktadır. Bunlar da:

Bir işten iyi anlayan, o işte becerikli olan usta bir kimse, ehil (erbab-ı ticaret, erbab-ı dil, erbab-1 sanat gibi)

Sahipler (erbab-ı vefa - vefa sahipleri, vefalı kimseler, erbab-ı himmet - himmet sahipleri, bir şey yapmak isteyenler)

Türk Dili ve Edebiyatı Ansiklopedisinde (TEA, 1977: cilt 3) erbap sözcüğünün "sahip" anlamında şu terkiplerde kullanıldığı belirtilmektedir:

$$
\begin{aligned}
& \text { erbab-ı hacat - iş sahipleri, işi olan kimseler } \\
& \text { erbab-1 kalem - kalem sahipleri, yazarlar }
\end{aligned}
$$


erbab-ı ukul - akıl sahipleri

erbab-ı bela - bela sahipleri, aşıklar

Erbap sözcügüu, ad olarak kullanılmasının yanısıra Türkçede çeşitli izafetler de kurmaktadır. Bu terkipler, Osmanlı döneminde ikinci unsuru Farsça ya da Arapça olan sıfat ve ad tamlamaları şeklinde geniş ölçüde kullanıldığı bilinmektedir. Devellioğlu'nun Osmanlıca-Türkçe Ansiklopeidk Lugat'inde erbap sözcüğü ile kurulan izafetlerin birçok örneği verilmekte (Devellioğlu, 2003: 226-227), sözcüğün ad ve sıfat olarak kullanım alanlarının ne kadar çeşitli olduğunu göstermektedir. Sözlükteki örneklerden bazıları şunlardır:

erbab-ı cah: zenginler, itibarlı, mevki sahibi kimseler

erbab-ı denaet: alçak kimseler

erbab-ı dil: gönül adamları

erbab-ı divan: 1. meclis. 2. devlet dairesi görevlileri

erbab-ı fenn: fen ile uğraşanlar, fen adamları

erbab-ı garaz: garaz sahipleri, kötü niyetliler

erbab-ı hacat: halkın ihtiyaçlarını karşılayan kimseler

erbab-ı hıred: sağduyu sahipleri

erbab-ı hiref: zanaatkarlar

erbab-ı himmet: himmet sahipleri, bir şey yapmak isteyenler

erbab-ı hüner: hüner sahipleri, sanatkarlar

erbab-ı iktidar: muktedir, iktidarlı kimseler

erbab-ı kalem: yazarlar

erbab-ı maali: itibarlı, saygın kişiler

erbab-ı ma'na: dindar kişiler

erbab-ı mesalih: işi olanlar, iş takip edenler

erbab-ı mütalaa: okuyanlar

erbab-1 namus: namuslular

erbab-ı sabahat-ü zarafet: güzel ve zarif kimseler

erbab-ı safa-yı batın: kalbi temiz, iman sahibi kimseler

erbab-1 sanat: sanatkarlar

erbab-1 servet: zenginler

erbab-ı seyf: kılıçla uğraşanlar

erbab-ı sika: inanılır, güvenilir kimseler

erbab-ı sühan: iyi konuşan kimseler

erbab-ı süluk: din işleriyle uğraşanlar, dindar kişiler

erbab-ı şikem: sırf boğazını düşünenler, boğazına düşkün olanlar

erbab-ı tab': tabiyat sahipleri, iyi yaratılılşlı kimseler

erbab-ı tagallüb: galip gelenler, üstün çıkanlar

erbab-ı temkin: temkinli kişiler

erbab-ı temyiz: basiretli, akıllı, anlayışlı, iyiyi kötüden ayırtedebilen kimseler

erbab-1 ticaret: ticaterle uğraşanlar 
erbab-ı vefa: vefa sahipleri, vefalı kimseler

erbab-ı vukuf: bilirkişiler

erbab-ı zahir: kainatın mahiyetini, ancak dış yüzüyle görenler, şeriatçlar.

\section{Erbap sözcüğünün Türkçede kullanılışı}

Türkçenin tarihsel gelişiminde eski dönemlerden beri erbap sözcüğünün yukarıda bahsedilen anlamlarıyla kullanım bakımından da büyük yelpaze çizmektedir. Erbap sözcüğü ile kurulmuş izafetlerin kullanımı günümüze kıyasla Osmanlı döneminde daha fazla olduğu önemle belirtilmelidir. Osmanlıca Lügatlere baktığımızda erbab maddesinde bu sözcükle kurulan terkiplerin sayısı Çağdaş Türkçe Sözlüklere göre bir hayli fazla olduğu görülmektedir.

Klasik Türk edebiyatında erbab-ı bela (aşıklar), erbab-ı sühan (söz sahipleri, şairler), erbab-ı dil (gönül adamları), erbab-ı aşk sıkça rastlanan terkiplerdendir. Bunlarla ilgili ünlü şairlerin eserlerinden birkaç örnek vermek yerinde olur. Divan şiirinde "bela”, "aşk belası, hasret, ayrılık, hicran, felaket, ölüm, azap, beddua" gibi bir çok anlamda ve tabirde geçmektedir. Divan şairlerinin en çok söz ettikleri bela ise "aşk belası"dır. Çünkü, Divan şairinin gözünde genel olarak sevgili ve aşı motifi bulunur. Şaire göre bu aşık, sevgilinin belasına düşmüş ve mübtela olmuştur (Çamyar 2015: 63).

Aşıkların ve söz ustaların nazarında aşk, gerçek hayattan soyutlanmış bambaşka bir alemdir ve bu alemi sadece aşk erbabı bilebilir, yani - "erbab-ı aşk, erbab-ı dil”.

XVII. yüzyll Türk şairlerinden Nef'i,

Meclis-i erbab-1 dil bir lahza sensiz olmasın

Hürmetin inkar eden alemde hürmet bulmasin (Nefi),

der.

Günümüz Türkçesiyle:

(Gönül erbablarının meclisi bir an sensiz olmasın, senin saygını inkar eden bu dünyada hürmet bulmasin)

Nedim, muvaffakiyetli bir imajla aşkın değerini ve kutsiliğini şu sözlerle ifade etmektedir:

Hac yollarında meş'ale-karban gibi

Erbab-ı aşk içinde nümayasın ey gönül (Nedim, XVIII. yy)

(Ey gönül, hac yollarındaki kervan meşalesi gibi aşılar içinde görünürsün)

Bu güzel beyitte şair aşkın zevk ve şevkiyle gönülleri dolmuş olanları, Allah'ın emirlerinden birini yerine getirmek için yola düşmüş bir kafileye benzetmektedir. Issız, karanlık çölleri aşan o kervanın yolunu nasıl en önde yanan bir meşale aydınlatırsa, aşıklar kafilesinin başında da şairin aşk ateşiyle olan gönlü parlamaktadır.

Edebiyatın ve şiirin temel malzemesi sayılan "sühan”, Farsça "söz, kelam, lafız, şiir" anlamındadır. Sözcük, birçok şairin eserlerinde erbab ile izafet oluşturarak geçmektedir. Erbab-ı sühan - söz sahipleri, söz üstaları, şairler anlamında kullanılmaktadır. Şeyh Galip’in dediği gibi: 
Erbab-ı sühan egerçi çokdur

bu neş'ede benden özge yokdur (Şeyh Galip)

Yine XVIII. yüzyllın renkli simalarından Sünbülzade Vehbi (1718-18o8) "sühan" kasidesini Sadrazam Halil Paşa'nın sadareti devrinde, zamanın değersiz şairlerini yermek ve onlara şiirin ne yolda yazılabileceği hakkında öğütler vermek için yazmıştır. Sadrazam Halil Paşa'nın emriyle yazılan Kemaliyye kasidesi, Sühan adıyla tanınmıştır (Kazan, 2004: 82). Şair, Halil Paşa'ya "Yüce sadaretinde devlet ile sağ olasın. Söz sahipleri, yani şairler şiirlerinde seni yüceltsinler” diyerek dua eder ve kasidesini şu sözlerle sonlandırır:

Sadr-ı rif atde heman devlet ile sağ olasın

Olsun erbab-ı sühan mahmidet-ara-yı sühan (Vehbi)

XVII. yüzyılın Osmanlı Divan Edebiyatı şairlerinden Bağdatlı Ruhi'nin Terkib-i Bend manzumesinde gözlemci ve eleştirel bakışaçısı sezilmektedir. Şair manzumenin birinci bendinde erbap sözcüğü ile kurulan iki terkip kullanmaktadır:

Erbab-i garez bizden irağ olduğu yeğdir

Düşmez yare zira okumuz sahib-i şeştüz

(Garaz sahiplerinin/kötü niyetliler bizden uzak olması daha iyidir. Çünkü okumuz yere düşmez, biz şast sahibi usta okçuyuz.)

Hem-kase-i erbab-ı dilüz arbedemiz yok

Mey-hanedeyüz gerçi veli ışk ile mestüz (Bağdatlı Ruhi)

(Gönül ehli ile aynı köşeyi paylaşırız, kavgamız yoktur. Meyhanedeyiz ama aşk ile sarhoşuz.)

Türk Edebiyat tarihinin ünlü isimlerinden Yahya Kemal Beyatlı’nın bir şiirinde "erbab-ı zeka” tabiri kullanılmıştır:

Rubai

Bilmem kime yahut neye uyduk gittik

Gâhî meye gâhî neye uyduk gittik

Erbâb-ı zekâ riya-yı mezhep bildi

Bizler dil-i divâneye uyduk gittik (Yahya Kemal Beyatlı)

Günümüz Türkçesiyle:

Bu dünyada kime yahut neye uyup gittik bilmem

Kimi zaman şaraba, kimi zaman da ney'e uyup gittik

Zeka sahipleri riyayı (iki yüzlülüğü) -kendilerine- yol bildi

Bizlerse gönlün deliliğine uyduk gittik

Namık Kemal'in en çok bilinen manzumelerinden biri Besalet-i Osmaniyye ve Hamiyyet-i İnsaniyye adıyla yayımlanan ve daha çok Hürriyet Kasidesi olarak bilinen şiiridir. Manzumenin bir beytinde "alçak, aşağılık kişiler" anlamında kullanılan erbab-ı denaet tamlamasına rastlanılmaktadır. Şairin zalimle devrin yöneticilerini alçak kişilerle de (erbab-ı denaet) bürokratları kasdetttiği malumdur. 
Mûini zalimin dünyada erbab-ı denaettir

Köpekdir zevk alan sayyad-ı bî-insafa hizmetten (Namık Kemal)

(Dünyada zalimin yardımcısı aşağılık kişilerdir. İnsafsız avcıya hizmet etmekten zevk alanlar ancak köpeklerdir)

Erbap sözcüğü Osmanlı döneminde daha geniş kullanıma sahip olduğunu söylemiştik. Osmanlı devletinde kamusal işlerin yürütülmesi doğrudan doğruya sultanın gözetiminde yapılmakta ve erbab-ı divan adı verilen ve önemli konularda öneri ve görüşlerini aktarmakla yükümlü olan üyelerden oluşan bir kuruldur.

Ayrıca erbap sözcüğü ile saray ve ordu gereksinimlerini karşılamakla görevli olan ve bu hizmetleri için devletten düzenli aylık alan zanaatkarlar topluluğu anılmaktadır. Zanaatkar sınıfından olan meslek sahipleri ise erbab-ı hiref (erbab-ı sanat) olarak bilinmektedir. XVI. yüzyıl ortalarında helvacıbaşı, çadır mehterleribaşı, alem mehterleribaşı, sakacıbaşı, mimarbaşı, kürkçübaşı, çizmecibaşı ve nakkaşbaşı olmak üzere aylıklı yedi hiref ağası vardır.

Temettuat defterleri genel itibariyle bir bölge hakkında bölgenin demografik yapısı, hane reisinin menkul ve gayr-i menkul kaynakları, yıllık kazancı, işletmelerin büyüklüğü, iş gücü ve ayrıntılı vergi yükü, kişilerin mesleği, yetiştirilen zirai ürün ve hayvanlar ile ticari ve sınaî müesseseler hakkında bilgiler sunmaktadır. Defterlerde, mahallelerdeki toplam hane sayısı, arazi miktarı, hane reislerinin meslekleri, yükümlü oldukları vergi miktarları gibi birçok konuda teferruatlı bilgiler bulunmaktadır. Meslekler, hane reisinin isminin üzerine eğik olarak yazılmıştır. Temettuat defterlerinde sıkça rastlanılan bir meslek bölümü erbab-ı ziraat olarak geçmektedir. Tarımla geçinen hane reisinin meslek bölümü "erbab-ı ziraattan idüğü", esnaflıkla geçinenlerinki ise "erbab-ı ticaretten idüğü" olarak belirtilmektedir. Ticaret ve ziraatın her ikisiyle geçimini sağlayanlar "erbab-ı ziraat ve ticaretten idüğü" şeklinde yazılmaktadır (Gül, 2009: 81).

Görüldüğü gibi erbap, Türkçede ad ve sıfat olarak, kurduğu izafet biçimleriyle değişik kullanımlarda her alanda görülebilir.

\section{Erbap sözcüğünün Bulgarcada anlamları ve kullanılışı}

Günümüze kadar Türkçeden Bulgarcaya geçen sözcüklerle ilgili birçok çalışma yapılmıştır. Bunlar, çeşitli açılardan ele alınıp incelenmiş, çalışmaların bir kısmı kitap olarak, bir kısmı da dergilerde makale olarak yayınlanmıştır. Türkçeden Balkan dillerine ve konkre olarak da Bulgarcaya geçmiş sözcüklerin anlam olayları en ilginç konulardan birini teşkil etmektedir.

Bulgarcada Türkçe sözcüklerden (Bulg. турцизми) bahsedilirken, aslında bunların Osmanlı döneminde Osmanlı İmparatorluğu'nun resmi dilinin etkisi ile, ayrıca halk tarafından kullanılan konuşma dilinin etkisi ile Bulgarcaya geçmiş Türkçe, Türkçe aracıllğı ile de Bulgarcaya geçmiş olan Arapça ve Farsça kökenli sözcükler olduğunu belirtmek gerekir. Bulgacaya giren sözcüklerin bazıları yeni dilinde yeni anlamlar edinir. Bu bağlamda Bulgarcadaki Türkçe sözcüklerin temel özelliklerinden biri anlam genişlemesi veya anlam kötüleşmesi, negatif bir durumu veya kişiyi karşlar hale gelmesidir diye söylenebilir. Bulgarcada gerek konuşma dilinde yaşamakta, gerek jargon dilinde kullanılmakta olan Türkçe sözcüklerden bir kısmı anlam kötüleşmesine uğrarken, erbap sözcüğü genel olarak olumlu anlamıla dilde kullanılmaya devam edilmektedir. 
Türkçe sözlüklerde erbap, tanımlar ve açıklamalara göre "bir işten anlayan, uzman, işi iyi yapan, sahipler, becerikli, bilen” anlamlarına sahip olduğunu yukarıda belirtmiştik.

Türkçeden kültürel ve dil etkileşimi sonucu Bulgarcaya giren erbap sözcüğü, Bulgarca açılamalı ve iki dilli sözlüklerdeki örneklerden, konuşma dilinde ad ve sıfat olarak geçtiği ve Türkçedeki anlamlarına uymlu olarak kullanıldığı anlaşılmaktadır:

ербап - познавач, майстор, специалисти (bilirkişi, uzman, usta) ( STR 1995; Yançev, 2007; Dobrev, 2009)

Türkçe-Bulgarca sözlüklerde epбan karşllı̆̆ında "Her işi erbabı bilir" (Yançev, 2007: 130), "Her işi erbabından sormalı" (Dobrev, 2009: 413) örnekleri verilmektedir.

Ancak, Bulgarcada bu anlamlara ek olarak erbap, “смел, наперен” - "cesur, kibirli, kendine güvenen, gururlu, mağrur” gibi yan anlamlar da kazanmaktadır. (STR, 1995). Bunun sebebi çok çeşitli olabilir. Dilciler, bir dilde sözcüklerin anlam değişmelerinin sebeplerini "dile dayalı sebepler, tarihi sebepler (nesneler, kurumlar, düşünceler), toplumsal sebepler, psikolojik sebepler, yabancı etkiden kaynaklanan değişmeler ve yeni bir ad ihtiyacından kaynaklanan değişmeler” olarak sinıflandırmaktadır (Ulman, 1972: 197-209). Örneğin, fikrimizce ayrı kişilerin bakış açısı, öznel değerlendirmeler, muhatap kişinin davranış ve tavırları yanlış ya da doğru tahminlere yol açabilir. Bilindiği gibi halk arasında bile "çok bilmiş" ile "kendini beğenmiş" sözleri hemen hemen aynı anlamlarda kullanılır. Çünkü insanlarda daha fazla bilgiye ve beceriye sahip olan kitlenin ya da kişinin daha az bilgi ve beceriye sahip olanları küçümsediği gibi bir takım düşünceler vardır ve bu da kimi zaman doğruluk payı taşımaktadır. Buna benzer benzetmelerin yanı sıra cesaretlinin daha az cesaretli olanları eleştirmeleri, zayıf görmeleri gibi durumlar da bilinir ve görülür. Dolayısıyla sözü geçen niteliklerden yoksun kişilerin üstün nitelikli ve beceriklileri "kendini beğenmiş ve kibirli" oldukları kanısına itmiş olabilir. Böylelikle erbap sözcüğü Bulgarcada "cesur, kibirli, kendine güvenen, gururlu" gibi yan anlamlar kazanmış olabilir.

Bütün bu açıklamalardan erbap, Bulgarcada iki yönde geliştiği anlaşılmaktadır. Biri, Türkçede bilinen anlamları, diğeri ise cesur, kibirli, kendine güvenen, gururlu anlamlarına sahip olduğudur. Çağdaş Bulgarcadaki günlük konuşma dilinde, edebi eserlerde, basın metinlerinde daha fazla yan anlamlarıyla kullanıldığı tespit edilmektedir. Aşağıdaki örnekler bunu açıkça göstermektedir. Bunların çoğunda halk arasında deyim niteliği kazanmış “Много си ербап, ама ...!” (çok erbapsın, ama ...!) sözünün anlam ve kullanımı ön plana çımaktadır.

Edebi eserlerden örnekler:

Не е за твоите уста лъжица тая работа, има от тебе по-ербап хора, нека те я измътят, па ний ще си проврем гагите - заявява наставнически бай Ганьо. (А. Константинов, Бай Ганъо: невероятни разкази за един съвременен българин, 1966)

"Bay Ganyo, bu iş senin ağzına sığacak kaşık değildir, senden daha erbap insanlar var, onlar açığa çıkarsın, biz gagamızı sokarız, diye nasihat verererek söyledi." (A. Konstantinov, Bay Ganyo) (akıllı, becerikli anlaminda)

Ако щеш вярвай, една косачка не може да бие по мощност която и да е дърворезачка, тя не изисква жилави ръце, с каквито е Лачко. Няма как да се похвали. Щото е ербап в главата и слаботелесен от рождение. (Николай Нинов, Врата за ада, XXII глава, 164) 
“İster inan, bir ot biçme makinası herhangi bir odun kesme makinasından daha güçlü olamaz, Laçko'nun elleri gibi sert ellere ihtiyaç yoktur. Övünmesi mümkün değildir. Çünkü kendisi kafadan erbaptır, ama doğuştan vücudu çelimsizdir.” (Nikolay Ninov, Cehennem Kapısı) (akıllı, becerikli anlamında)

Не разбирам, и това е! Аз ти казах как стана при мене! А пък тези шюкюри им пращат! Ако са толкова ербап защо бягат, ами не стоят там, да се бият с московците! (Киряк Цонев, Жаравата ражда огън, 2007, 271)

"Anlamadım, o kadar! Bende nasıl olduğunu sana söyledim! Bunlar ise onlara şükürler gönderiyor! Bu kadar erbap iseler, neden orada durup moskovla savaşmak yerine kaçıyorlar.” (K. Tsonev, Közlerden Ateş Doğar) (cesur, kendine güvenen)

А ти си получи заслуженото. Просветна ли ти? И друг път не бъди толкова ербап! - отговори Светлин (Янко Долапчиев, Забранените майки, 1996, с. 32)

"Svetlin: "Sen hakettiğini aldın, aklın başına geldi mi? Bundan sonra da bu kadar erbap olma! diye cevap verdi.” (Y. Dolapçiev, Yasak Anneler) (cesur, kendine güvenmek)

Hepimizin bildiği gibi, medya toplumla en çok ilişki kuran bir kurumdur. Gerek sokakta yapılan bir röportajda, izlenme oranı yüksek programlarda, gerek gazete ve dergilerde kullanılan dil çok önemlidir. Bulgaristan'da Bulgarca yayımlanan yazılı basında Türkçe sözcüklerin kullanımı daha çok medya dilinin günlük konuşma diline yaklaştırılmasına yönelik olduğu düşüncesi ileri sürülmektedir.

V. Krısteva'ya göre, basında kullanılan ve günden güne çoğalan Türkçe sözcükler, daha özgün bir ifade elde etmekle beraber, bir olayı, kişiyi veya durumla ilgili ifadeyi negatif anlama yönlendirmek için uygun bir araç olduğunu belirtmektedir (Krısteva, 2000: 9).

T. Boyadjiev, gazeteci ile okur arasındaki iletişimin başarılı olabilmesi için, haber yazarı metnini hem içerdiği bilgi bakımından, hem de metin dili bakımından kitleye uygun olarak hazırlanması gerektiğini, bu da konuşma dilinden unsurlar kullanılarak sağlanabileceğini belirtmektedir (Boyaciev, 2008: 5).

H. Mevsim ile K. Çakırova Bulgar basınında kullanılan Türkçe sözcüklerin anlam özelliklerini değerlendirerek kullanımlarına dair eleştirel bir analiz yapmışlardır. Araştırmacılar, gazetelerde büyük sayıda kullanılan sözcüklerin anlamları Türkçedeki anlamlarıyla geçiştiğini tespit etmektedir (Mevsim, Çakırova 2007).

Bu görüşlerin tam aksine Em. Pernişka ise, "günümüzde çlkan Bulgar gazetelerinde toplum tarafından eskimiş, günlük konuşmada kullanılan sözcükler ve unutulmaya yüz tutumuş Türkçe sözcükler olarak değerlendirilen kelimeler medya dilini çirkinleştirir” fikrini ileri sürmektedir (Pernişka, 1999: 131)

Bütün bunlara ramen erbap sözcüğünü bulunduran birçok basın metni arasından seçtiğimiz şu örnekleri dikkatinize sunuyoruz:

Как не остана поне един ербап и лицеприятен политик, че да яхне протеста ... "Protestoda önderlik edecek bir erbap siyasetçi nasıl da kalmadı" (Novinar 13.02.07)

Нашите ербапи разчитат още веднъж да излъжат гласоподавателите на местните избори ... "Вizim erbaplar yerel seçimlerde seçmenlerin bir kez daha kandırılmasına güvenmektedir” (Trud, 10.07.2017) 
Най-ербап го даде британският военен министър Уйлямсън. Той се изпъчи и предупреди ... “Еn büyük erbaplığı İngiltere Savunma Bakanı Williamson gösterdi. Kendisi cesurca kalkıp uyarıda bulundu ...” (Duma, 45, 07.03.2018)

Haber başlıkları:

Eрбап дядо намушка двама полицаи. “Erbap dede iki polisi bıçakladı.”

Ха сега да видим дали си ербап. До 150 лева глоба, ако не дадеш път на линейка.

"Hadi bakalım ne kadar erbapsın. Ambulansa yol vermezsen, 150 levaya kadar para cezası"

Erbap sözcüğünün Türkçedeki anlam boyutundan başka farklı yanı da Bulgarcada tamlama olarak değil, sözcüğün basit şekli ve türevleri kullanılmasıdır:

ербаплия - erbapliya (erbaplı) - sıfat olarak “cesur ve kabiliyetli” anlamında (BER 1971)

ербаплък - erbaplık (erbaplık)- ad olarak “eskiden kahramanlık, cesurluk” anlamlarında kullanılmıştır.

\section{Sonuç}

Sonuç olarak denilebilir ki, diller arası alış verişte ve etkileşmede, dil dışı öğeler daha çok belirleyicidir. Yani dili daha eski, köklü ve güçlü olan değil, siyasi, askeri ve ekonomik bakımdan daha güçlü olanların dili etkileyen, verici dil durumuna gelir. Türk dili Bulgarların Türklerle ilişkileri dahilinde Bulgar dilinin tarihi gelişiminde önemli rol oynamış, dil yapısında değişimlere sebep olmuştur. Türk dilinin Bullgarca üzerindeki yoğun etkisi XIX. yüzyılın sonuna kadar devam eder. Günümüzde bu etkileşim kaçınılmaz bir şekilde konuşma ve jargon dilinde, bölge ağızlarında, sözlü halk kültüründe hala devam ettiği de söylenebilir. Dil ilişkileri sonucu Bulgarcaya giren erbap sözcüğü bu alışverişin bir örneğidir. Türkçede Arapçadan girmiş olup genellikle izafetler kurarak Osmanlı döneminde bir hayli geniş kullanıma sahip olan erbap sözcüğü, Bulgarcada Türkçedeki anlamlarıyla sınırlı kalmamış, yan anlamlar kazanmıştır.

\section{Kaynakça}

Aksan, D. (1978).Anlambilimi ve Türk Anlambilimi (Ana Çizgileriyle). DTCF, Ankara

Boyaciev, T. (2008) Ezikovata situatsia u nas v istoriçeski i sıvremenen plan i evropeyskata ezikova politika. Bılagaski ezik, Sofya, kn. 3

Devellioğlu, F. (2003). Osmanlıca-Türkçe Ansiklopedik Lugat. Ankara, 2003.

Dobrev, İ. (2009). Tursko Bılgarski Akademiçen Reçnik. İvan Dobrev, Riva, Sofya

Gül, A. (2009). Temettuat Defterlerine Göre Pasinler’in (Hasankale) Sosyal Ve Ekonomik Yapısı, Karadeniz Araştırmaları, Cilt: 6, Sayı: 23, Güz 2009, s.77-98.

Çamyar, E. (2015). Fuzuli Ve Baki Divanı'nda Bela Kavramının Karşılaştırılması. Dede Korkut Türk Dili Ve Edebiyatı Araştırmaları Dergisi 1 (2): 58-99.

Kazan, Ş. (2004). Divan Şiirinde Önemli Bir Leitmotif: Sühan Redifli Siirler. Çankaya Üniversitesi FenEdebiyat Fakültesi Journal of Arts and Sciences, Sayl 2, Aralık, 2004, s. 75-104.

Krısteva, V. (2000). Reçnik na turskite dumi v sıvremennia bılgarski ezik. Sofya.

Mevsim, H., Çakırova, Kr. (2007) Otnovo za sıdbata na turtsizmite v sıvremenniya bılgarski ezik (izolatsiya i/ili reabilitatsia). 7.10.2007, 15.06.2010;

http://www. liternet.bg/ 
Pernişka, E. (1999). Za "groznoto" v naşiya ezik i ezika na mediite. // Mediite i eziktt, Sofya.

Sefercioğlu, M., N., (2019). Yazı ve Yazı ile İlgili Unsurların Divan Şiirinde Kullanılışı. URL: http://www.geocities.com/msefercioglu/makaleler/divansiirindeyazi.htm (Erişim tarihi: 25.03.2019)

Stamenov, M. (2011): Sidbata na turtsizmite v bilgarskiya ezik i v bılgarskata kultura. Sofya, İztokZapad.

Ulman, S. (1972). Semantics. An Introduction to The Science of Meaning, Oxford Basil Blackwell, London

Yançev, M. (2007). Türkçe-Bulgarca, Bulgarca-Türkçe Sözlük. Riva, Sofya.

\section{Kisaltmalar}

STR 1995: Sivremenen tılkoven reçnik na bılgarskiya ezik s prilpjeniya. St. Burov, V. Bocolova, M. İlieva, P. Pehlivanova, Treto izdanie.

TEA 1977: Türk Dili ve Edebiyatı Ansiklopedisi. Devirler, İsimler, Eserler, Terimler. Degrah Yayınları.

TБР 2004: Tursko-bılgarski reçmik. L. Dimitrova. Veliko Tirnovo.

TS 1998: Türkçe Sözlük, TDK, Ankara. 